\title{
Bamabi L. Chapin.Childhood in a Sri Lankan Village: Shaping Hierarchy and Desire. Rutgers University Press, New Brunswick, New Jersey and London, 2014, p. 211.
}

\author{
Harini Amarasuriya \\ Open University of Sri Lanka
}

Ever since I heard of Bambi Chapin's work I have been waiting eagerly to read it: an ethnographic study on childhood and child rearing in a Sinhala village is an extremely valuable addition to the body of anthropological work in Sri Lanka. It is all the more valuable, because for the past several years, anthropologists have focussed almost exclusively on examining Sri Lankan society and culture through the lens of violence and ethnicity. Chapin's work marks a welcome return to other equally important analytical categories and themes with which we can examine Sri Lankan society.

Chapin's book is based on ethnographic fieldwork conducted in a Sinhala village she calls Viligama close to Kandy. Viligama is considered by the residents of Kandy to be a "poor, low-caste area with residents of questionable moral habits" (pg. 9). As Chapin says, the book is not a typical 'village' study - it is about how children's behaviour, social relationships and cultural frameworks are shaped through their experiences with others.

The central question that drives Chapin's interest in child rearing practices in Sri Lanka is how it is that Sri Lankan children seem to transition from tantrum throwing, demanding little tyrants around the age of two years to passive, compliant and undemanding older children. Drawing from both anthropology and psychology, Chapin argues that children draw from central cultural models in learning how to negotiate the social relationship around them. Culture is transmitted through the everyday interactions the children have with their closest caregivers and their peers. While child behaviours and particular parenting techniques may look the same across cultures, their particular meaning can only be understood within a specific cultural context. Thus, Chapin claims, that ideas about desire and hierarchy are central to the cultural models that Sinhalese children learn through their everyday interactions. They learn, for instance, that uncontrolled desires are dangerous and they learn to control these desires from an early age; they also learn 
a particular model of hierarchy that shapes their interactions both within and outside their homes. The reactions of those around them to certain behaviours, the emotions that are attributed to certain actions teach children these important cultural values and modes of being.

Chapin's rich ethnographic detail provides a fascinating and insightful account of family, kinship relations, child rearing practices and childhood in a Sri Lankan village. However, in emphasising 'culture' as the main category through which these practices and relationships can be viewed, there is sometimes the tendency to slip into a somewhat uncritical use of culture as a deterministic 'thing' out there that is the most important source of meaning making in this village. There is also a tendency to regard the 'culture' of Viligama village as reflective of certain dominant 'cultural models' in Sri Lanka. Although, Chapin is careful, particularly in her conclusion to point to the dynamism of culture, the way in which 'primary' and 'secondary' institutions are interwoven, this is not always evident in the way in which the ethnography is presented.

For instance, I would have liked to have known a little bit more about why desire and hierarchy were the main cultural models in Viligama. Is this different from the cultural models elsewhere in Sri Lanka? For example, some of the child rearing techniques described by Chapin with regard to mothers' reactions to their children's temper tantrums is not the same as what I have observed (of course not through any formal study) elsewhere. There are Sinhala mothers who would relate far more with how Chapin reacted to her own son's behaviour than to how mothers in Viligama reacted. How do we account for these differences? Does the specific socio-economic context of Viligama emphasise certain values more than others? Just as much as Chapin makes the important point that there is tremendous diversity between American models of child rearing practices and Sri Lankan practices, there are also differences within Sri Lankan child rearing practices and it would be extremely interesting to understand how and why. Of course, Chapin's study is an in-depth ethnographic study of a specific context, but her emphasis on 'culture' as the main source of difference may obviate how some of the structural aspects such as class, status, caste, etc., influence people's everyday interactions and indeed shape particular cultural models. 
For instance, Chapin's fascinating account of how the idiom of envy is used to make sense of relationships, particularly between peers, is very convincing. However, I was left with the question as to whether it was simply 'shared cultural models' that explained how envy became such a crucial aspect of social relationships in Viligama. It still does not explain how envy became such a potent idiom within those cultural models. Could the relatively deprived circumstances in Viligama have some bearing on this?

Chapin also makes the important point that cultural models keep shifting. Her analysis of recent educational reforms and how parents and teachers understood and responded to these reforms also shows how cultural models are affected by larger political and economic processes. The way in which specific attitudes and practices are also interwoven with more systemic processes provides a broader interpretation of the context within which certain cultural models are produced and sustained. This is an aspect I wish Chapin had dealt with more in relation to some of the other sections as well.

This is an important contribution to the body of anthropological knowledge in Sri Lanka and a fascinating read. It raises some important issues on personhood and specifically childhood in Sri Lanka which are areas which have not been seriously dealt with by scholars previously. It has opened up a fresh area of work for Sri Lankan scholars. 